\title{
Three phase induction motor torque tracking algorithm based on the rotor time constant identification
}

\author{
Najimaldin M. Abbas' ${ }^{1}$, Dawood N. Saleh², Ali M. Shakor ${ }^{1}$ \\ ${ }^{1}$ Department of Electrical Engineering, College of Engineering, University of Kirkuk, Kirkuk, Iraq \\ ${ }^{2}$ Department of Electrical Engineering, College of Engineering, University of Mosul, Mosul, Iraq
}

\begin{tabular}{l} 
Article Info \\
\hline Article history: \\
Received Oct 6, 202 \\
Revised Jan 13, 2022 \\
Accepted Jan 20, 2022 \\
\hline Keywords: \\
Induction motor \\
Rotor time constant \\
Small signal model \\
Torque model \\
Tracking
\end{tabular}

\begin{abstract}
The indirect vector control system can realize the on-line identification of the rotor time constant based on electromagnetic torque. However, still effective range of the torque model is suitable only for heavy load conditions. In this paper, an improved torque tracking model is constructed by modifying the conventional torque model with rotor time constant identification. Through the establishment of the small signal model of the identification system, the stability of the torque model is deeply analyzed, and it is concluded that the torque model has two balance points, namely the expected balance point and the error balance point; the error balance point limits the scope of the torque model root cause. The simulation show that the problem of unbalance point can be avoided with the aid of the proposed algorithm. In addition, the design ideas of proportional-integral adaptive law parameters are given from the two perspectives of system stable operation and optimal convergence process.
\end{abstract}

This is an open access article under the CC BY-SA license.

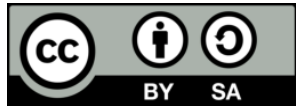

\section{Corresponding Author:}

Najimaldin M. Abbas

Department of Electrical Engineering, College of Engineering, University of Kirkuk

Kirkuk, Iraq

Email: dralbyati@uokirkuk.edu.iq

\section{INTRODUCTION}

The indirect field oriented control (IFOC) scheme is widely used in high-performance induction motor drive occasions due to its simple structure and high reliability [1]. The rotor time constant is a key parameter to achieve rotor field orientation and high-performance control [2]. However, in practical applications, the rotor inductance will change with the degree of magnetic saturation of the motor, and the rotor resistance will be affected by changes in the internal temperature of the motor [3], [4]. The deviation of the rotor time constant will lead to wrong field orientation, which will deteriorate the system control performance [5], [6].

Many researches have conducted in-depth research and proposed many online identification schemes for rotor time constants. Hasan and Husain [7] combines the advantages of Romberg observer and sliding mode observer, and proposes a Romberg-sliding mode observer to realize on-line identification of rotor resistance. Tran et al. [8] uses dual sliding mode surfaces to achieve simultaneous correction of rotor resistance and slip gain (the reciprocal of the rotor time constant). Ammar et al. [9] uses the voltage response information in the transition process to modify the rotor time constant. In [10], [11] uses the high frequency information of certain physical quantities in the reference adaptive system model (RASM) speed observer to realize the identification of the rotor time constant. In [12]-[15] uses signal injection, artificial neural network, and extended Kalman filter to realize the on-line identification of the rotor time constant. Among many identification algorithms, the identification algorithm based on RASM is favored by people because of 
its easy implementation and good stability [1]. Many algorithms has different implementation forms depending on the selected physical quantity, such as q-axis rotor flux model [16], [17], d-axis stator voltage model [18], [19], reactive power model [1], [5], [20], [21], electromagnetic torque model [22]-[25]. Abdalla et al. [20] established a unified mathematical model of this type of identification system, revealing the internal connection between different identification models. Bermúdez et al. [23] comprehensively compared several identification schemes from the perspectives of deviation sensitivity, convergence speed, parameter dependence, and pointed out that each scheme has its limitations; according to different applications, the optimal identification model can be selected. Rashag et al. [21] pointed out through steadystate analysis that the rotor time constant identified by the torque model cannot converge to its true value under certain load conditions. Mohamed and Habbi [22] pointed out that in the full load interval, the polarity of the torque deviation is not always consistent. Bermúdez et al. [23] proves through experiments that when different rotor time constants are deviated, the torque-current curves overlap in the light load region. Cao et al. [24] uses the unified RASM theory to prove that the torque model does not satisfy the lyapunov stability condition when the load is small. The existing In has a more comprehensive analysis of the torque model, and pointed out that the torque model is only suitable for the heavy load condition of the motor. Nevertheless, the research on the torque model still has the following shortcomings: the stability of the identification system requires further in-depth analysis; for the problem of the limited action interval of the torque model, the existing in rarely mentions the improvement scheme. Chutisant [25], proposed interesting extended particle filter to recognition hand writing. Theparcticl filter can used as a new idea that may be directly applied to the stability analysis of the rotor time constant identification system based on the torque model.

In this paper an improved torque model by simply modifying the torque tracking equation in the conventional torque model was proposed. There are two balance points in the torque model, namely, the desired balance point and the error balance point by solving the steady-state balance point. The value of the rotor time constant at the unbalance point not only depends on the real rotor time constant value of the motor, but also is affected by the load ratio (the ratio of the torque current to the excitation current). The model can avoid unbalance point is the leading factor that causes the instability and limitations of the torque model, and the selection of inappropriate regulator parameters will cause system instability. In addition, the model regulate parameters from two perspectives: the stable operation of the system and the optimization of the convergence process.

\section{THEORETICAL BCKGROUND}

\subsection{Mathematical model of induction motor}

In the dq synchronous rotating coordinate system, the dynamic mathematical model of induction motor based on indirect vector control can be expressed as [2]:

$$
\begin{aligned}
& v_{s}=R_{s} i_{s}+\sigma L_{s} \frac{d}{c t} i_{s}+J_{2} \omega_{c} \sigma L_{s} i_{s}+J_{2} \omega_{c} \frac{L_{m}}{L_{r}} \psi_{r}+\frac{L_{m}}{L_{r}} \frac{d}{d t} \psi_{r} \\
& \frac{d}{d t} \psi_{r}=\frac{L_{m}}{\tau_{r}} \psi_{r}-\frac{1}{\frac{d}{d t} \psi_{r}} \psi_{r}-J_{2} \omega_{s} \psi_{r} \\
& \omega_{s}=\frac{i_{s q}^{*}}{\hat{\tau}_{r} i_{s d}^{*}}
\end{aligned}
$$

where: $v_{s}=\left[v_{s d} v_{s q}\right]^{T} 、 i_{s}=\left[i_{s d} i_{s q}\right]^{T}, \psi=\left[\psi_{s d} \psi_{s q}\right]^{T}$ are the stator voltage and stator respectively in the dq synchronous rotating coordinate system Current and rotor flux linkage; $\tau_{r}$ is the real rotor time constant of the motor, "^" represents the estimated value; $\omega_{e} 、 \omega_{r}, \omega_{s}$ are the synchronous electrical angular velocity, rotor electrical angular velocity, and slip electrical angular velocity, respectively; $R_{S}$ is the stator resistance, $L_{m}, L_{r}, L_{s}$ are the motor excitation inductance, stator inductance, and rotor inductance respectively; $J_{2}=$ $\left[\begin{array}{cc}0 & -1 \\ 1 & 0\end{array}\right] ; \frac{\sigma=1-L_{m}^{2} 2 m}{L_{S} L_{r}}$; superscript "*" indicates the command value.

\subsection{Conventional torque model}

The torque model proposed is realization block diagram [22]. The actual torque expression has been incorporated into the adaptive PI gain. The mathematical expression of the conventional torque model can be expressed as [22]:

Three phase induction motor torque tracking algorithm based on the rotor time ... (Najimaldin M. Abbas) 


$$
\begin{aligned}
& T_{\text {eref }}=i_{s \beta} \psi_{r \alpha}-i_{s \alpha} \psi_{r \beta}=i_{s q} \psi_{r d}-i_{s d} \psi_{r q} \\
& T_{e e s t}=L_{m} i_{s q} i_{s d} \\
& \frac{1}{\hat{\tau}_{r}}=\frac{1}{\tau_{\text {rini }}}+k_{p T} \Delta T+\int k_{i T} \Delta T d t
\end{aligned}
$$

where: $\Delta T=T_{e r e f}-T_{e e s t} ; k_{p T}$, and $k_{i T}$ are proportional and integral adaptive gains respectively. Due to the symmetry of the torque expression with respect to the torque current, the following will take the positive torque current condition as an example for analysis.

\section{PROPOSED METHOD}

Figure 1 shows the block diagram of the rotor time constant online identification system based on the improved torque model. As shown in Figure 1, $i_{s q} \psi_{r d}-i_{s} d \psi_{r q}$ is selected as the physical quantity in the traditional torque model. In the case of accurate magnetic field orientation, that is, $\psi_{r d}=L_{m} i_{s d}$ and $\psi_{r q}=0$, the physical quantity is equal to $L_{m} i_{s q} i_{s d}$ :

$$
\begin{aligned}
& X_{r e f}=i_{s q} \psi_{r d}-i_{s d} \psi_{r q} \\
& X_{\text {est }}=L_{m} i_{s q} i_{s d} \\
& \frac{1}{\hat{\tau}_{r}}=\frac{1}{\tau_{\text {rini }}}+k_{p} \Delta \mathrm{X}+\int k_{i T} \Delta \mathrm{X} d t
\end{aligned}
$$

where $\Delta X=X_{\text {ref }}-X_{e s t} ; k_{p}, k_{i}$ are proportional integral coefficients. Let the differential term in (2) be 0 , the steady-state rotor flux in the $d q$ coordinate system can be obtained as (10).

$$
\left\{\begin{array}{l}
\psi_{r d}=L_{m} i_{s q} \frac{i_{s d}^{2}+\frac{\tau_{r}}{\hat{\tau}_{r}} i_{s q}^{2}}{\left(\frac{\tau_{r}}{\tau_{r}}\right)^{2} i_{s q}^{2}+i_{s d}^{2}} \\
\psi_{r q}=L_{m} i_{s d} \frac{i_{s d} i_{s q}\left(1+\frac{\tau_{r}}{\hat{\tau}_{r}}\right)}{\left(\frac{\tau_{r}}{\hat{\tau}_{r}}\right)^{2} i_{s q}^{2}+i_{s d}^{2}}
\end{array}\right.
$$

The steady state $\Delta X$ expression simultaneous (7)-(10) can be (11).

$$
\Delta X=L_{m} i_{s q} i_{s d} \frac{i_{s d}^{2}+\frac{\tau_{r}}{\tau_{r}} i_{s q}^{2}}{\left(\frac{\tau_{r}}{\tau_{r}} i_{s q}\right)^{2}+i_{s d}^{2}}\left(\frac{\tau_{r}}{\hat{\tau}_{r}}-1\right)
$$

The steady-state $\Delta T$ expression in the conventional torque model can combine (4), (5) and (10) and be obtained (12).

$$
\Delta T=L_{m} i_{s q} i_{s d} \frac{i_{s d}^{2}-\frac{\tau_{r}}{\tau_{r}} s_{s q}^{2}}{\left(\frac{\tau_{r}}{\tau_{r}} i_{s q}\right)^{2}+i_{s d}^{2}}\left(\frac{\tau_{r}}{\hat{\tau}_{r}}-1\right)
$$

It can be seen that compared with the conventional torque model comparing (11) and (12), the estimated slip gain value at the error balance point $E P_{F}$ of the proposed scheme is a negative number $-1 /\left(\tau_{r} k_{t}{ }^{2}\right)$. Therefore, the proposed algorithm can naturally avoid the problem of wrong balance point. If the stability of the system at the desired balance point is also ensured, the proposed scheme is globally stable.

The RASM method construct with a new physical quantity $X=i_{s q} \psi_{r d}+i_{s} d \psi_{r q}$. In the case of accurate magnetic field orientation, the physical quantity mentioned is also equal to $L_{m} i_{s q} i_{s d}$. This is why the algorithm proposed in this paper is called an improved torque model. In fact, the variable $\mathrm{X}$ is a fictitious physical quantity with no physical meaning. Using the variable $\mathrm{X}$ as the set physical quantity in the RASM can naturally avoid the unbalance point in the traditional torque model, which will be described detail in section result and discussion. 


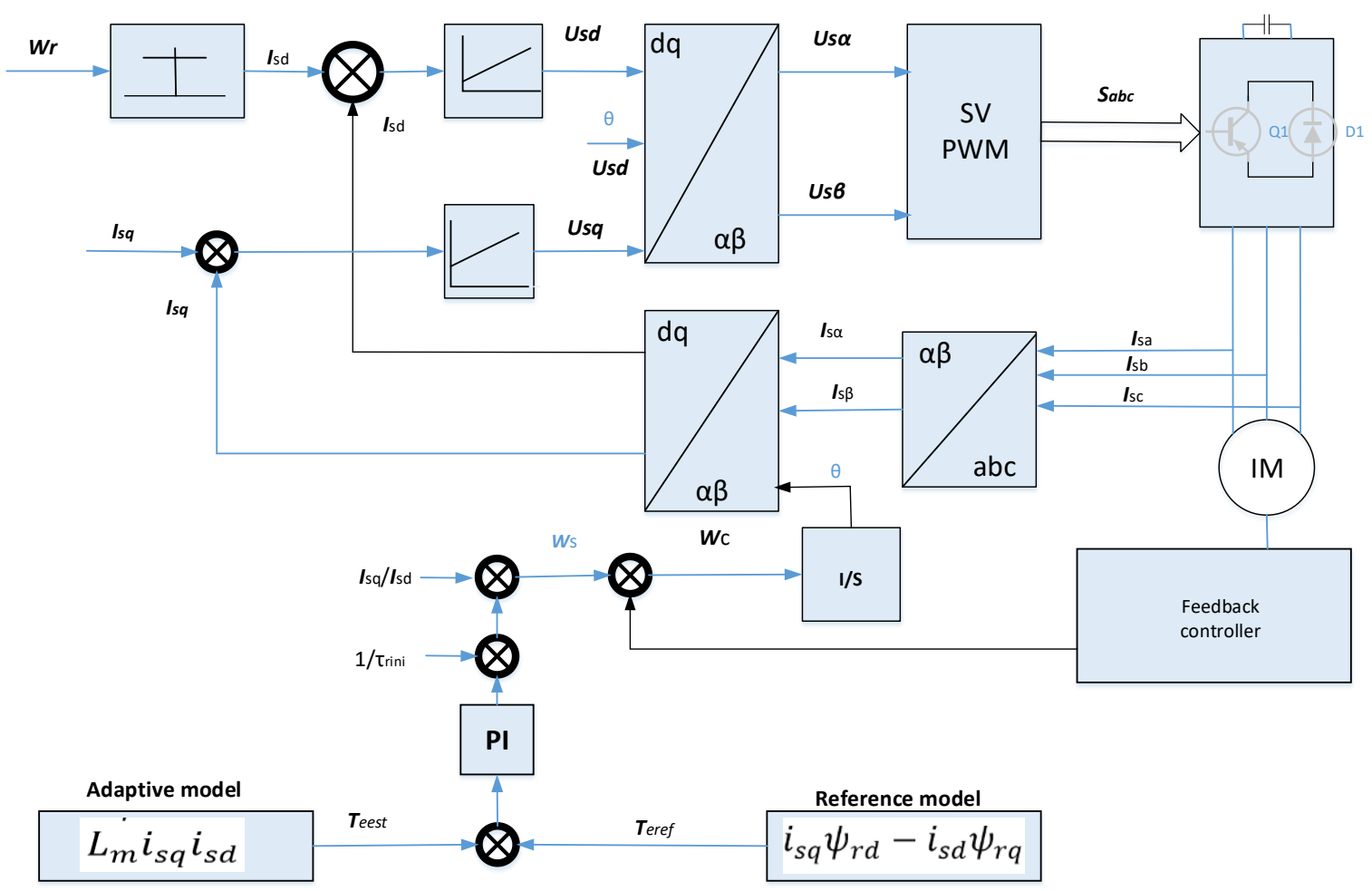

Figure 1. Overall proposed model

\section{RESULTS AND DISCUSSION}

In this section the conventional torque model with rotor time constant identification models were developed for $3 \mathrm{hp}$ induction motor. In order to verify the correctness of the proposed theory and design scheme, a simulation platform composed of a set of $10 \mathrm{~kW}$ induction motor as shown in Table 1 . The table consists in the rated value of power, voltage, curremt, frequency, stator and rotor resistance, rotor nd stator inductance.

Table 1. Induction motor parameters

\begin{tabular}{lclc}
\hline \multicolumn{1}{c}{ Parameter } & Value & \multicolumn{1}{c}{ Parameter } & Value \\
\hline Power $(\mathrm{kW})$ & 10 & Stator resistance $(\Omega)$ & 0.076 \\
Voltage $(\mathrm{V})$ & 220 & Rotor resistance $(\Omega)$ & 0.055 \\
Current $(\mathrm{A})$ & 32 & Stator inductance $(\mathrm{mH})$ & 14.1 \\
Frequency $(\mathrm{Hz})$ & 100 & Rotor inductance $(\mathrm{mH})$ & 14.1 \\
Pairpole & 2 & Mutual inductance $(\mathrm{mH})$ & 13.6 \\
\hline
\end{tabular}

\subsection{Conventional torque model experiment}

In this section also investigate the influence of PI regulator parameters on the stability of the identification system [18]. The experiment in this section will focus on verifying the correctness of the theoretical analysis. Figure 2 shows the identification simulation waveforms of the torque model with different PI parameters under the conditions of $i_{s q}=40 \mathrm{~A}$ and $\mathrm{n}=1200 \mathrm{r} / \mathrm{min}$. According to (7), it can be seen from Figure 2(a) that under the condition of $k_{p T}=0$, the integral coefficient must satisfy $k_{i T}<2.8$ to ensure the stability of the system. From Figure 2(b), when $k_{i T}=4$, it can be seen that the identification system collapses. According to (6), it can also be obtained: when the integral coefficient is fixed at 1 , the proportional coefficient must be less than 0.721 to avoid instability. From Figure 2(c), it can be seen that when $k_{p T}=0.8$ and $k_{i T}=1$, the identification system collapses. It can be found that the simulation results are consistent with the theoretical analysis, which proves the correctness of the theoretical analysis. 


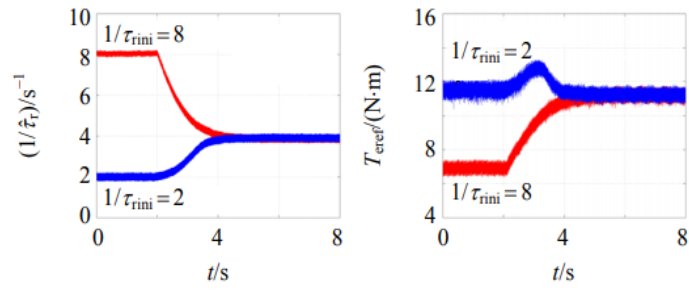

(a)

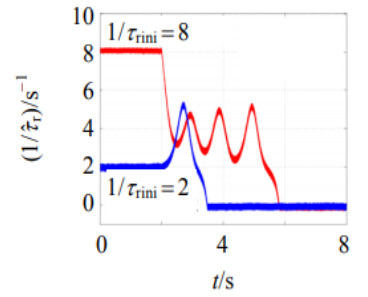

(b)

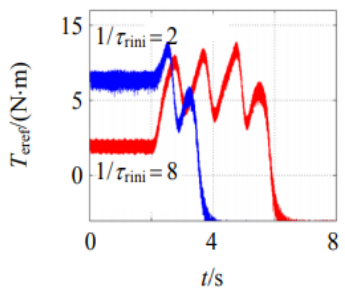

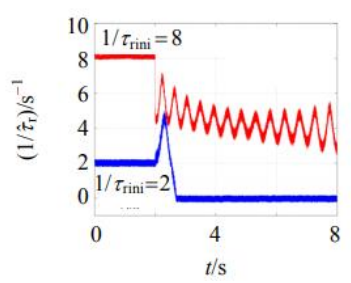

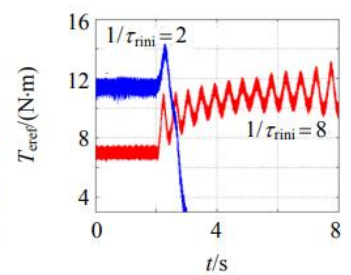

(c)

Figure 2. Simulation result of rotor time constant identification of conventional torque model: (a) $K_{p T}=0$, $k i T=1$, (b) $K_{p T}=0, k i T=4$, and (c) $K_{p T}=0.8, k i T=1$

\subsection{Proposed torque model}

When the motor speed is $1200 \mathrm{r} / \mathrm{min}$, this section selects two typical torque current values for experiments to verify the proposed algorithm, $i_{s q}^{*}=10 \mathrm{~A}$ and $40 \mathrm{~A}$. When $k_{i}=1,3$ Figures 3 (a) and (b) respectively show the rotor time constant identification simulation waveforms of the proposed RASM under two working conditions. From Figure 3, it can be seen that the proposed algorithm can achieve accurate identification of the rotor time constant under different torque currents, which proves that the proposed algorithm can effectively broaden the working range of the conventional torque model. It can be found from the simulation results: when the torque current is small $(10 \mathrm{~A})$, with the increase of $k_{i}$, the identification parameter convergence speed will increase; when the torque current is large (40 A), with the increase of $k_{i}$ Increase, the identification parameters appear under-damped oscillation process. Under the same two groups of torque currents, Figure 4 shows the results of the rotor time constant identification experiment using the proposed integral coefficient design scheme for case (a) at $i_{s q}=10$ A and for case (b) $i_{s q}=40$ A. From Figures 4(a) and (b), it can be found that the optimal parameter convergence process can be realized at different operating points using the design strategy proposed in this paper.
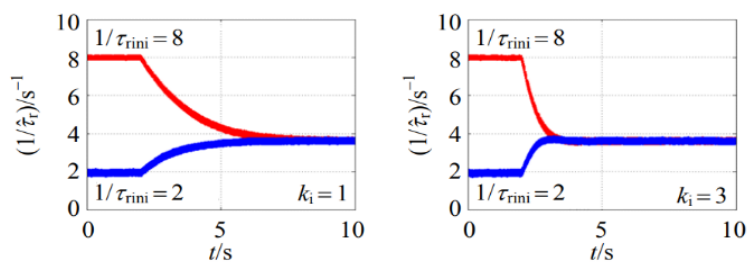

(a)
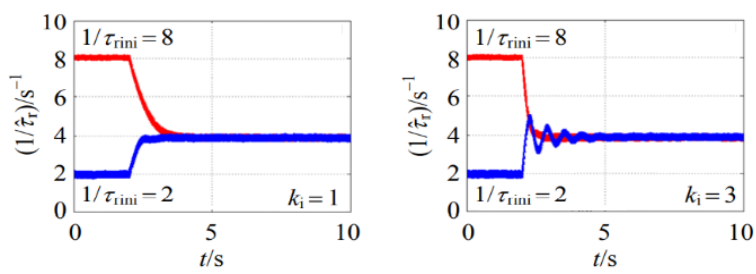

(b)

Figure 3. The rotor time constant with different integral coefficients: (a) $i_{s q}=10 \mathrm{~A}$ and (b) $i_{\mathrm{sq}}=40 \mathrm{~A}$
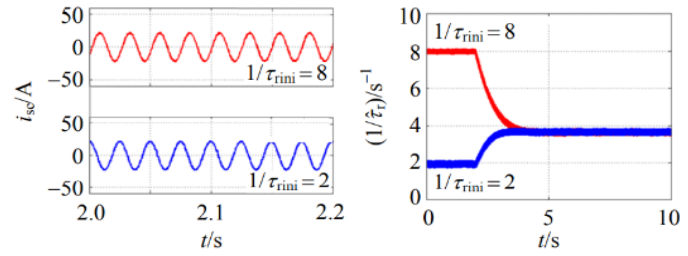

(a)
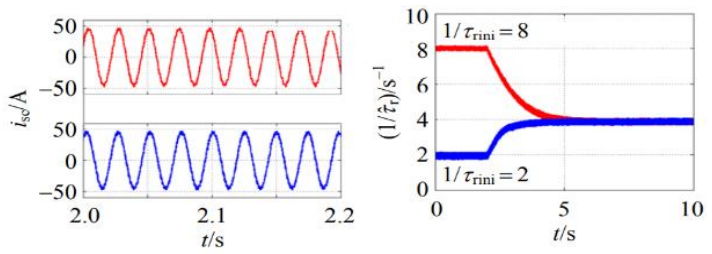

(b)

Figure 4. The online rotor time constant of the integrated coefficient: (a) $\mathrm{i}_{\mathrm{sq}}=10 \mathrm{~A}$ and (b) $\mathrm{i}_{\mathrm{sq}}=40 \mathrm{~A}$ 
Figure 5 shows the rotor time constant identification experiment results when the motor runs at $30 \mathrm{r} / \mathrm{min}$ and torque current $40 \mathrm{~A}$. From Figure 5, it can be found that the proposed algorithm can also achieve accurate identification of the rotor time constant at lower speeds. When the motor speed is fixed at $1200 \mathrm{r} / \mathrm{min}$, the torque current command changes according to 40, 30, 20, 10, 40, and $10 \mathrm{~A}$. At this time, the corresponding motor phase (A) current are shown in Figure 6(a), and the slip gain identification waveform is being presented in Figure 6(b). From Figure 6, it can be seen that the identification value of the rotor time constant changes with the torque current command. The reason for this phenomenon is the existence of nonideal factors such as iron loss and stray loss in real motors.
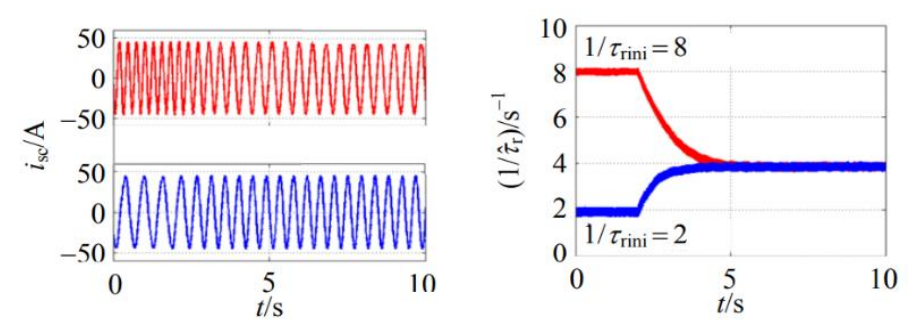

Figure 5. The online identification of the time constant of the RASM rotor

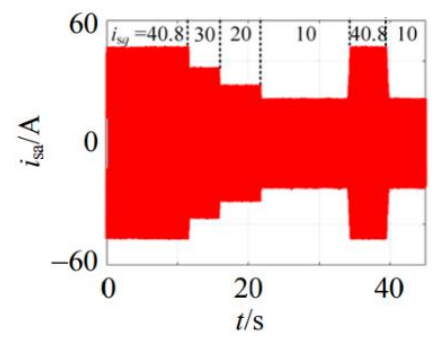

(a)

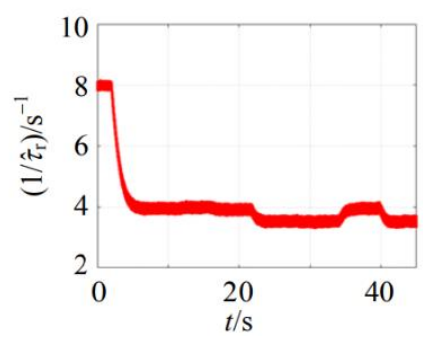

(b)

Figure 6. The slip gain and $i_{s a}$ during torque current step: (a) $i_{s a}$ simulation result and (b) differential gain

Table 2 shows the actual output torque measured by the torque meter after the deviation of the theoretical output torque, the rotor time constant for orientation, and the identification algorithm for different torque current commands. The simulation result is that the motor is tested at a stable speed of $1200 \mathrm{r} / \mathrm{min}$. From Table 2, it can be found that when $1 / \tau_{r}=8 s-1$ and the torque current command value is small, the actual output torque is greater than the theoretical torque. As the torque current increases, the actual output torque will be less than that. Theoretical value. When the identification algorithm is enabled, the torque control accuracy can be effectively improved. Table 2 shows, from the simulation data it also can observe that even after the identification algorithm is enabled, the output torque is still slightly less than its theoretical value. The reason for this phenomenon is that the motor iron loss branch will occupy a part of the stator current $q$ axis component. How to compensate the impact of iron loss and other non-ideal factors on the torque control accuracy will be the focus of the author's subsequent research work.

Table 2. Theoretical and measured torque values before and after identification

\begin{tabular}{cccc}
\hline \multirow{2}{*}{ Current (A) } & \multirow{2}{*}{ Reference torque $(\mathrm{N} \cdot \mathrm{m})$} & \multicolumn{2}{c}{ Tracking torque $(\mathrm{N} \cdot \mathrm{m})$} \\
& & 6.32 & 3.23 \\
& 3.79 & 9.24 & 6.91 \\
5 & 7.68 & 10.61 & 10.82 \\
10 & 11.6 & 11.91 & 14.25 \\
15 & 15.2 & 12.92 & 18.32 \\
20 & 19.3 & 14.52 & 22.01 \\
25 & 23.1 & 15.61 & 25.52 \\
30 & 26.8 & 17.59 & 29.57 \\
35 & 31.2 & & \\
40 & &
\end{tabular}




\section{CONCLUSION}

This paper introduced an improved torque model by modifying the reference torque calculation equation. The model integrate two indicators of stable operation of the system and optimized convergence process to give the idea of selecting the PI parameters. The experiment verifies the correctness of the theoretical analysis and the proposed scheme. In order to further improve the motor control performance, future work will focus on the estimation of the rotor flux linkage and the compensation of non-ideal factors such as iron loss.

\section{ACKNOWLEDGEMENTS}

The authors grarfull to Department of Electrical Engineering, at the University of Kirkuk and University of Mosul for their support.

\section{REFERENCES}

[1] S. Maiti, C. Chakraborty, Y. Hori, and M. C. Ta, "Model Reference Adaptive Controller-Based Rotor Resistance and Speed Estimation Techniques for Vector Controlled Induction Motor Drive Utilizing Reactive Power," in IEEE Transactions on Industrial Electronics, vol. 55, no. 2, pp. 594-601, Feb. 2008, doi: 10.1109/TIE.2007.911952.

[2] S. S. Keream, A. N. Abdalla, and M. R. Daud, "Nonlinear Dynamic Inverse Controller Based In Field Oriented With SVPWM Current Control," Pertanika Journal of Science \& Technology, vol. 25, no. 102, pp. 37-44, 2017.

[3] N. T. García, Y. A. G. Gómez, and F. E. H. Velasco, "Parameter estimation of three-phase linear induction motor by a DSP-based electric-drives system," International Journal of Electrical and Computer Engineering, vol. 10, no. 1, pp. 626-636, 2020, doi: 10.11591/ijece.v10i1.pp626-636.

[4] B. L. G. Costa, C. L. Graciola, B. A. Angélico, A. Goedtel, M. F. Castoldi, and W. C. de A. Pereira, "A practical framework for tuning DTC-SVM drive of three-phase induction motors," Control Engineering Practice, vol. 88, pp. 119-127, 2019, doi: 10.1016/j.conengprac.2019.05.003

[5] S. Aryza, A. N. Abdallah, Z. Khalidin, Z. Lubis, and M. Jie, “A Fast Induction Motor Speed Estimation based on Hybrid Particle Swarm Optimization (HPSO)," Physics Procedia, vol. 25, pp. 2109-2115, 2012, doi: 10.1016/j.phpro.2012.03.357.

[6] G. Ruzlaini, A. N. Abdalla, and Z. Sujod, "Direct Torque Control for matrix converter-fed three phase induction motor with hybrid PSO," Journal of Theoretical and Applied Information Technology, vol. 13, pp. 36-40, 2010.

[7] S. M. N. Hasan and I. Husain, "A Luenberger-sliding mode observer for online parameter estimation and adaptation in highperformance induction motor drives," IEEE Trans. on Industry Applications, vol. 45, no. 2, pp. 772-781, 2009, doi: 10.1109/TIA.2009.2013602

[8] C. D. Tran, P. Brandstetter, M. C. H. Nguyen, S. D. Ho, B. H. Dinh, and P. N. Pham, "A robust diagnosis method for speed sensor fault based on stator currents in the RFOC induction motor drive," International Journal of Electrical and Computer Engineering, vol. 10, no. 3, pp. 3035-3046, 2020, doi: 10.11591/ijece.v10i3.pp3035-3046.

[9] A. Ammar, A. Kheldoun, B. Metidji, T. Ameid, and Y. Azzoug, "Feedback linearization based sensorless direct torque control using stator flux MRAS-sliding mode observer for induction motor drive," ISA Transactions, vol. 98, pp. 382-392, 2020, doi: 10.1016/j.isatra.2019.08.061.

[10] R. Mini, B. P. Shabana, B. H. Satheesh, and M. N. Dinesh, "Low Speed Estimation of Sensorless DTC Induction Motor Drive Using MRAS with Neuro Fuzzy Adaptive Controller," International Journal of Electrical and Computer Engineering, vol. 8, no. 5, pp. 2691-2702, 2018, doi: 10.11591/ijece.v8i5.pp2691-2702.

[11] V. R. Jevremovic, V. Vasic, D. P. Marcetic, and B. Jeftenic, "Speed sensorless control of induction motor based on reactive power with rotor time constant identification," IET Electric Power Applications, vol. 4, no. 6, pp. 462-473, 2010, doi: 10.1049/ietepa.2009.0208.

[12] L. Zhang, H. Zhang, H. Obeid, and S. Laghrouche, "Time-varying state observer based twisting control of linear induction motor considering dynamic end effects with unknown load torque," ISA Transactions, vol. 93, pp. 290-301, 2019, doi: 10.1016/j.isatra.2019.03.008

[13] K. Wang, B. Chen, G. Shen, W. Yao, K. Lee, and Z. Lu, "Online Updating of Rotor Time Constant Based on Combined Voltage and Current Mode Flux Observer for Speed-Sensorless AC Drives," in IEEE Transactions on Industrial Electronics, vol. 61, no. 9, pp. 4583-4593, Sept. 2014, doi: 10.1109/TIE.2013.2288227.

[14] B. Karanayil, M. F. Rahman, and C. Grantham, "Online Stator and Rotor Resistance Estimation Scheme Using Artificial Neural Networks for Vector Controlled Speed Sensorless Induction Motor Drive," in IEEE Transactions on Industrial Electronics, vol. 54, no. 1, pp. 167-176, Feb. 2007, doi: 10.1109/TIE.2006.888778.

[15] M. Barut, S. Bogosyan, and M. Gokasan, "Experimental Evaluation of Braided EKF for Sensorless Control of Induction Motors," in IEEE Transactions on Industrial Electronics, vol. 55, no. 2, pp. 620-632, Feb. 2008, doi: 10.1109/TIE.2007.911956.

[16] S. Aryza, A. N. Abdalla, Z. Khalidin, and Z. Lubis, "Adaptive Speed Estimation of induction motor Based on Neural network Inverse Control,” Procedia Engineering, vol. 15, pp. 4188-4193, 2011, doi: 10.1016/j.proeng.2011.08.786.

[17] S. Yang, P. Cao, and X. Zhang, "Stability analysis of q-axis rotor flux based model reference adaptive system updating rotor time constant in induction motor drives," in CES Transactions on Electrical Machines and Systems, vol. 1, no. 2, pp. 109-116, 2017, doi: 10.23919/TEMS.2017.7961292.

[18] T. Englert and K. Graichen, "Nonlinear model predictive torque control and setpoint computation of induction machines for high performance applications," Control Engineering Practice, vol. 99, 2020, doi: 10.1016/j.conengprac.2020.104415.

[19] S-P. Koh, S-K. Tiong, K. Ali, and A. Abdalla, "Fuzzy Logic Enhanced Direct Torque Control with Space Vector Modulation," Indonesian Journal of Electrical Engineering and Computer Science, vol. 11, no. 2, pp. 704-710, 2018, doi: 10.11591/ijeecs.v11.i2.pp704-710.

[20] A. N. Abdalla, Z. Lubis, M. Mohamed, Z. M. Ali, and M. A. M. Hussin, "A new series-parallel hybrid electric vehicle configuration based on an induction motor coupled to a DC machine," Scientific Research and Essays, vol. 5, no. 24, pp. 4034-4043, 2010. 
[21] H. F. Rashag, S. P. Koh, K. H. Chong, S. K. Tiong, N. M. L. Tan, and A. N. Abdalla, "High performance of space vector modulation direct torque control SVM-DTC based on amplitude voltage and stator flux angle," Research Journal of Applied Sciences, Engineering And Technology, vol. 5, no. 15, pp. 3934-3940, 2013, doi: 10.19026/rjaset.5.4455.

[22] H. A. Mohamed and H. M. D. Habbi, "Power quality of dual two-level inverter fed open end winding induction motor," Indonesian Journal of Electrical Engineering and Computer Science, vol. 18, no. 2, pp. 688-697, 2020, doi: 10.11591/ijeecs.v18.i2.pp688-697.

[23] A. Bermúdez, D. Gómez, M. Piñeiro, and P. Salgado, "A novel numerical method for accelerating the computation of the steadystate in induction machines," Computers \& Mathematics with Applications, vol. 79, no. 2, pp. 274-292, 2020, doi: 10.1016/J.CAMWA.2019.06.032.

[24] P. Cao, X. Zhang, and S. Yang, "A Unified-Model-Based Analysis of MRAS for Online Rotor Time Constant Estimation in an Induction Motor Drive," in IEEE Transactions on Industrial Electronics, vol. 64, no. 6, pp. 4361-4371, June 2017, doi: 10.1109/TIE.2017.2668995.

[25] C. Kerdvibulvech, "Human Hand Motion Recognition Using an Extended Particle Filter," International Conference on Articulated Motion and Deformable Objects, 2014, pp.71-80, doi: 10.1007/978-3-319-08849-5_8.

\section{BIOGRAPHIES OF AUTHORS}
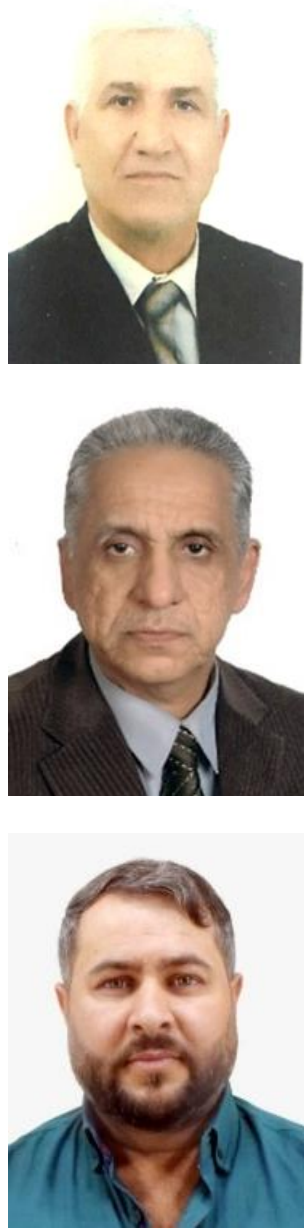

Najimaldin M. Abbas (D) IS SC P received M.Sc in Electrical Engineering from Baghdad University, Baghdad, Iraq in 1978 and Ph.D in Electrical Engineering from Southampton university Electrical Engineering, UK, 1989. Currently working as assistance Prof. with department of Electrical Engineering, University of Kirkuk, Iraq. Research interested in Electrical machine, control, Modelling, artificial intelligence, and optimization. He can be contacted at email: dralbyati@uokirkuk.edu.iq.

Dawood N. Saleh (iD 8) SC P was born in Mosul, Iraq, in 1963. He received the B.Sc. degree in electrical engineering from the University of Mosul, Mosul, in 1987, the M.Sc. degree in pulsed power technology from the University of Strathclyde. Glasgow. U.K., and the Ph.D. degree in high-voltage gaseous insulation from the university of Mosul, Mosul, Iraq in 2019. In 1992, he joined the Department of Electrical Engineering, University of Mosul. His current research interests include high-voltage insulation, gaseous discharge, and partial discharge detection. He can be contacted at email: dnsaij@uomosul.edu.iq.

Ali M. Shakor (iD 8d SC P received BSc in Electrical Engineering from Tikret University, Tikret, Iraq in 2009 and M.Sc in Electrical Engineering from California state University Fullerton, USA, 2017. Currently working as Ass. Lecturer. with department of Electrical Engineering, University of Kirkuk, Iraq. Research interested in Control, optimization, Modelling and Machine learning. He can be contacted at email: ali.doub88@uokirkuk.edu.iq. 